\title{
President's Message: Join Us at the Forum!
}

$\mathrm{T}$ he first LITA National Forum I attended was in Milwaukee, Wisconsin. It seems like it was only a couple of years ago, but in fact nine National Forums have since passed. I was a new librarian, and I went on a lark when a colleague invited me to attend and let me crash in her room for free. I am so glad I took her up on the offer because it was one of the best conferences I have ever attended. It was the first conference that I felt was made up of people like me, people who shared my interests in technology within the library. The programming was a good mix of practical know-how and mindblowing possibilities. My understanding of what was possible was greatly expanded, and I came home excited and ready to try out the new things I had learned.

Almost eight years passed before I attended my next Forum in Cincinnati, Ohio. After half a day I wondered why I had waited so long. The program was diverse, covering a wide range of topics. I remember being depressed and outraged on the current state of Internet access in the United States as reported by the Office for Information Technology Policy. I felt that surge of recognition when I discovered that other universities were having a difficult time documenting and tracking the various systems they run and maintain. I was inspired by David Lanke's talk, "Obligations of Leadership." If you missed it you can still hear it online. It is linked from the LITA Blog (http:// www.litablog.org).

While the next Forum may seem like a long way off to you, it is in the forefront of my mind. The National Forum 2010 Planning Committee is busy working to make sure this Forum lives up to the reputation of Forums past. This year's Forum takes place in Atlanta, Georgia, September 30-October 3. The theme is "The Cloud and the Crowd." Program proposals are due February 19, so I cannot give you specifics about the concurrent sessions, but we do hope to have presentations about projects, plans, or discoveries in areas of library-related technology involving emerging cloud technologies; software-as-service, as well as social technologies of various kinds; using virtualized or cloud resources for storage or computing in libraries; library-specific open-source software (OSS) and other OSS "in" libraries; technology on a budget; using crowdsourcing and user groups for supporting technology projects; and training via the crowd.

Each accepted program is scheduled to maximize the impact for each attendee. Programming ranges from five-minute lightening talks to full day preconferences. In addition, on the basis of attendee comments from previous Forums, we have also decided to offer thirty- and seventy-five-minute concurrent sessions. These concurrent sessions will be a mix of traditional single- or multispeaker formats, panel discussions, case studies, and demonstrations of projects. Finally, poster sessions will also be available.

While programs such as the keynote speakers, lightning talks, and concurrent sessions are an important part of the Forum experience, so is the opportunity to network with other attendees. I know I have learned just as much talking with a group of people in the hall between sessions, during lunch, or at the networking dinners as I have sitting in the programs. Not only is it a great opportunity to catch up with old friends, you will also have the opportunity to make new ones. For instance, at the 2009 National Forum in Salt Lake City, Utah, approximately half of the people who attended were first-time attendees. The National Forum is an intimate event whose attendance ranges between 250 and 400 people, thus making it easy to forge personal connections. Attendees come from a variety of settings, including academic, public, and special libraries; library-related organizations; and vendors. If you want to meet the attendees in a more formal setting you can attend a networking dinner organized on-site by LITA members. This year the dinners were organized by the LITA president, LITA past president, LITA presidentelect, and a LITA director-at-large.

If you have not attended a National Forum or it has been a while, I hope I have piqued your interest in coming to the next National Forum in Atlanta. Registration will open in May! The most up-to-date information about the 2010 Forum is available at the LITA website (http:/ / www.lita.org). I know that even after my LITA presidency is a distant memory, I will still make time to attend the LITA National Forum. I hope to see you there! 